\title{
Investigating the Influence of Business Intelligence on the Quality of Decision Making in an Indonesian Fertilizer company
}

Dekar Urumsah

Faculty of Business and Economics, Universitas Islam Indonesia, Yogyakarta, Indonesia dekar.urumsah@uii.ac.id

Heri Ramadhansyah

Faculty of Business and Economics, Universitas Islam Indonesia, Yogyakarta, Indonesia

Follow this and additional works at: https://journal.uii.ac.id/jca

Copyright (C2019 Journal of Contemporary Accounting and Authors.

To cite this article: Dekar Urumsah, Heri Ramadhansyah (2019). Investigating the Influence of Business Intelligence on the Quality of Decision Making in an Indonesian Fertilizer company. Journal of Contemporary Accounting, 1(2), 120-129. doi:10.20885/jca.vol1.iss2.art5 


\title{
Investigating the influence of business intelligence on the quality of decision making in an Indonesian fertilizer company
}

\author{
Dekar Urumsah ${ }^{1}$, Heri Ramadhansyah ${ }^{2}$ \\ 1,2 Faculty of Business and Economics, Universitas Islam Indonesia, Yogyakarta, Indonesia
}

JEL Classification:

M15, D81

\section{Keywords:}

Business intelligence, quality of decision making, Indonesian fertilizer company

Corresponding Author:

dekar.urumsah@uii.ac.id

DOI:

$\underline{10.20885 / \text { ica.vol1.iss2.art5 }}$

Copyright (C) 2019

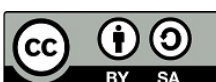

This is an open access under CC-BY-SA license

\begin{abstract}
This study investigates the factors influencing the quality of decision making in Indonesian fertilizer sector. Business intelligence management, business intelligence scope, data quality, content quality, and information quality are the examined factors. Empirical study was conducted through survey questionnaire from top and operational managers who operated a business intelligence system. A structural equation modelling using Partial Least Square is condected through the analysis of 111 usable the questionnaires. The results of the study show that business intelligence management is the main factors influencing the quality of decision making. The study contributes to both academia and industry by provide new insights for managers regarding to the influence of business intelligence on the high quality of decision making. This could serve as a guideline for organizations in understanding the important factors that should be considered when deciding to improve the quality of decision making.
\end{abstract}

\section{Introduction}

Recently, Business Intelligence (BI) has became a top priority of Information Technology and Communication (ICT) department in most companies to increase organization performance. The market of related software products remains to raise quicky in line with a trend of Business Analytics (BA) and Big Data Management that has contributed to grow of BI software market. This is inseperable from the role of management that has contributed to the sustainable growth of BI software market (Wieder \& Ossimitz, 2015) in particular to assist in the decision making process. It is because BI system can handle large amounts of information and be able to identify such information to develop new opportunities, one of which is a market advantage. The use of BI tools can also help to increase profits by managing organisational corporate performance and gain competitive advantage through consolidation of past victories (O’Brien \& Marakas, 2011). Hence, BI can have a significant impact on company performance and therefore it is considered a high priority for many companies in today's business environment (Hawking \& Sellitto, 2010).

The main objective of BI tools is to convert data into meaningful and valuable information. According to Wieder and Ossimitz (2015), the main objective of BI is to provide high quality information for managerial decision making. This is attempted using essentially a two-stage approach: (a) identification, collection, storage and maintenance of data, and (b) retrieving, processing and conveying (communicating/presenting) data in a way which is useful for the receiver/decision maker.

Although prior studies have focused on the application of BI, an investigation concerning the influence of business intelligence on the quality of decision-making is still limited in 
Indonesia. Regarding BI implementation and decision-making, there have been several theoretical views and empirical studies on these two topics (Monfared \& Akbari, 2019; O'Brien \& Marakas, 2011; Stefan, 2009; Wieder \& Ossimitz, 2015). However, most of the studies did not focus on the impact of BI towards the quality of decision-making, especially in the scope of fertilizer company. Moreover, this study also added content quality as mediation between BI and quality of decision making.

The fertilizer company in this study is the complete fertilizer producer in Indonesia producing a wide range of fertilizer and non-fertilizer products, so it is not surprising if the data managed by the company every day is very large. Therefore, BI is very helpful for this company in managing all of the data into the information, which in turn facilitate decision-making.

This research discusses the quality of decision-making by taking into account the influential factors or aspects of BI. The purpose of this study is to know: first, the impact of BI management on the quality of decision-making, BI scope, content quality, data quality, and information quality; second, the impact of data quality on information quality; third, the impact of BI scope, content quality, and information quality on the quality of decision-making. By focusing on the influence of BI toward the quality of decision-making, this study will provide new insights for managers about the influence of BI aspect on the high quality of managerial decision-making. This could serve as a guideline for organizations in understanding the important factors that should be considered when to decide to implement BI so that organizations could achieve effective and efficient decisions.

This article is devided into four parts: the first part contains literature review on Business Intelligence management and quality of decision making. The second part presents the research methodology used in this study. The third part comprises of the results and analysis. In this part the data is analysed using Partial Least Square (PLS) based on Structured Equition Model (SEM). The last part consists of discussions, implications and conclusions of the research.

\section{Literature Review}

\section{Business Intelligence}

Business Intelligence (BI) is a process of applying tools and techniques to gather and analyse the data collected from multiple (both internal and external) sources, to create knowledge that helps in decision making (Sohollo, 2011). Other than that, BI can also be defined as a multidimensional concept concerning the attention to effective dissemination of organizational practices, processes, and technologies to create a knowledge base that supports an organization (Olbrich et al., 2012).

Wieder and Ossimitz (2015) states interrelationship between BI management with data quality, information quality, and the scope of BI in influencing decision making. While other research conducted by Hadeel (2012) explains that the influence of quality of content to decision making.

Hence, BI implementation aspects used in this study are based on the previous research by combining the research undertaken by Wieder and Ossimitz (2015) and Hadeel (2012) about the influence of BI implementation on the quality of decision making using Information Systems Success Model (DeLone \& McLean, 2003).

\section{Quality of Decision Making}

Decision-making is one of the characteristics that define leadership and it is indeed the duty of managers and employees so that the companies can still operate and grow (Wieder et al., 2012). Therefore, managers and employees of the same level of managers should pay attention to the importance of quality decision-making in the company's operations. The quality of decision making can be influenced by various factors, one of that is experience and decision in the past. 
Past Experiences and decisions made in the past may affect decision making by managers in the future (Juliusson et al., 2010). It is well-founded that when a decision makes positive things, managers are more likely to decide in the same way, considering the same given situation. In fact, the decision made in the future, which is based on past experience is not necessarily the best decision. As in financial decision making, highly successful individuals do not make investment decisions based on their bad experiences in the past. This approach contrasts with what might be expected (Hadeel, 2012). The significant factors that influence the decisionmaking process include past experience, various cognitive biases, an escalation of commitment, individual differences, including age and social status, economics, and beliefs in personal relevance (Juliusson et al., 2010). A high-quality decision should be supplemented by evidence in form of a guarantee, not a guarantee of a particular outcome, but a guarantee that the process used to achieve goals is the right choice (Hadeel, 2012).

\section{Business Intelligence Management}

From a theoretical perspective, argued by Wieder and Ossimitz (2015) that BI management (managing purpose and strategy; implementation; and support of BI systems) has a positive effect on data quality, information quality, and the scope of BI (number of business functions or processes supported by BI tools). BI management capabilities can be interpreted as thinking of the resources and learning processes needed to combine BI software with corporate strategy into the BI systems, and to ensure the success of objectives related to the BI process (Dawson \& Van Belle, 2013).

The success of BI management also requires the alignment of IT with business across BI cycle (Wieder \& Ossimitz, 2015). If resources from IT departments and business needs are aligned through appropriate BI management, companies can realize the potential benefits of BI applications (Wieder \& Ossimitz, 2015). Thus, BI management will not only affect objectives achievement, that is quality decision making in terms of BI process directly, but also affect other aspects such as BI scope, content quality, data quality, and information quality. Therefore, the hypotheses are proposed as follows:

H1: BI management has a positive impact on the quality of decision making.

H2: BI management has a positive impact on the BI scope.

H3: BI management has a positive impact on the content quality.

H4: BI management has a positive impact on the data quality.

H5: BI management has a positive impact on the information quality.

\section{Data Quality}

Data are closely related to information. Data quality, refers to the quality of representation of relevant facts. The distinction between data (quality) and information (quality) is particularly evident in the BI context. Through BI, collecting and saving data, as well as knowledge management can be combined with analytical tools to present complex and competitive internal information for decision makers. The main objective of BI is to provide high quality information for managerial decision making. The hierarchical relationship of data and information implies that data quality is a pre-requisite or antecedent - but not a guarantee - of information quality (Wieder \& Ossimitz, 2015). This explains that quality information can be obtained when data used has high quality. Data can be interpreted to have high quality if they are suitable with the usefulness in operational activities, decision-making, and planning (Redman, 2008). Corporate data either external or internal are converted into information that can help companies to achieve goals, opportunities, and corporate position (Wieder et al., 2012). So, quality information can be gained when data used have high quality. Thus, data are an important component in the success 
of BI system implementation. Their existence is inevitable and should have good quality. Therefore, a hypothesis is proposed as follows:

H6: Data quality has a positive impact on the information quality.

\section{Business Intelligence Scope}

BI scope is a variation in various applications applied or implemented at each stage of corporate operational activities (Wieder \& Ossimitz, 2015). Various software products offered in support of BI system vary in term of goal or role, function, functional scope, and level of sophistication (Peters \& Wieder, 2013).

By the BI scope, BI system can be accepted and used easily and is suitable for the individual goals (Hou, 2014). Better BI management is expected to have two impacts on the BI scope. Firstly, the direct impact of the increased success of BI system. Secondly, successful BI management will build trust in BI resulting in higher diffusion of BI applications across various business functions (Wieder \& Ossimitz, 2015). Thus, either with or without BI management support, it is expected that BI scope with the wide and varied applications can help facilitate the organization or company in determining a decision. Therefore, a hypothesis is proposed as follows:

H7: BI scope has a positive impact on the quality of decision making.

\section{Content Quality}

Content is also one of the components that determine BI success (Hadeel, 2012). If the content quality is not good, it can affect decision-making process, which will indirectly affect operational continuity of the company. Content quality in this study is user perception of the quality figure, quality improvement, investigation ability, and content interpretation ability (Hadeel, 2012). Companies that implement BI system in accordance with existing content have more advantages and will continue to grow (Korte et al., 2013). Therefore, the hypothesis is proposed as follows: H8: Content quality has a positive impact on the quality of decision making.

\section{Information Quality}

Information quality is described as desired characteristics of the information system and type of information that is desired (DeLone \& McLean, 2003). In relation to information quality, it is defined as the completeness, accuracy, format, and currency information generated from the process of the system. Completeness is intended on the ability of the system in providing all the information required. Accuracy refers to perceptions of the system users that the available information is correct. The format is the user perception of how well the information presented. Meanwhile, currency is the user perception of the updated information in decision support system (Venkatesh et al., 2013).

In relation to information, information itself can be linked to the future, which in turn can be a relevant decision (Juliusson et al., 2010). Information reduces the uncertainty of decision makers by helping to identify existing alternatives and predicting the consequences of the selected alternatives (Wieder \& Ossimitz, 2015). Thus, to make the right decisions and get profitable, effective, and efficient results, an organization or a company needs to take into account the information; it should be assured and has high quality. Therefore, a hypothesis is proposed as follows:

H9: Information quality has a positive impact on the quality of decision making.

Based on the above literature review and hypotheses development generated, the research model is shown in Figure 1 that illustrates the research model of determinant factors of quality of decision making. 


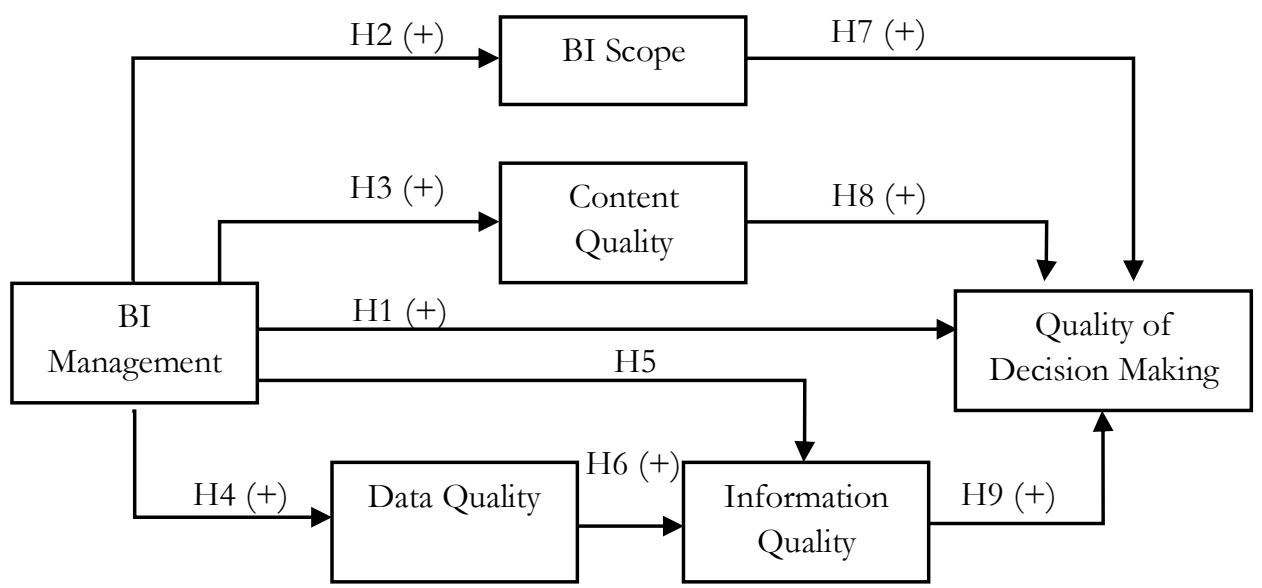

Figure 1. Research Model of Quality of Decision Making Support Aspects

In this research model, BI management measures the quality of decision making directly and also measures BI scope, content quality, data quality, and information quality. In the meantime, data quality measures the information quality from the BI system, while BI scope, content quality, and information quality measure the quality of decision-making. To put it simply, BI management, data quality, BI scope, content quality, and information quality independently and together affect the achievement of decision-making quality.

\section{Research Method}

Data for this study was collected using structured questionnaire by survey in one of the biggest Indonesian fertilizer companies. A total of 130 questionnaire forms were delivered to respondents of which 111 were returned giving a response rate of 85 percent. Questionnaires were distributed directly by visiting the respondents' workplace at the head office. The questionnaires were distributed to all divisions in the company- marketing, finance, production, technical and development, human resources and general divisions.

\section{Variables and Measurement}

The present research has six variables that are BI management, BI scope, data quality, content quality, information quality, and quality of decision-making. It makes use of Likert scale as the measurement scale by using interval 1-6 in measuring the respondent opinion on each statement. The answer of each instrument indicator using the Likert scale has the gradation from the highest to the lowest value or grade. A range of answer options starts from Strongly Agree with a score of 6, Agree with a score of 5, Somewhat Agree with a score of 4, Somewhat Disagree with a score of 3, Disagree with a score of 2, and Strongly Disagree with a score of 1 . The higher score of a variable means the respondent's opinion on a statement is higher; a lower score of a variable means the respondent's opinion on a statement is lower according to the user perception. The items to measure variables of this study are illustrated in Table 1.

Table 1. Measurement items

\begin{tabular}{lcl}
\hline \multicolumn{1}{c}{ Variables } & Measurement & \multicolumn{1}{c}{ Resources } \\
\hline BI management & 3 items & \\
BI Scope & 2 items & Wieder dan Ossimitz (2015) \\
Content Quality & 5 items & \\
\hline Data Quality & 5 items & Hadeel (2012) \\
\hline Information Quality & 5 items & Wieder dan Ossimitz (2015) \\
\hline Quality of Decision Making & 4 items & Hadeel (2012) \\
\hline
\end{tabular}




\section{Results and Discussion}

\section{Statistical Samples}

Overall, the respondents in this fertilizer company are mostly male, that are 97 respondents $(87.39 \%)$ and female are 14 respondents (12.61\%). The most dominant age was 20-29 years old that are 64 respondents $(57.66 \%)$. The majority of respondents had completed bachelor's degree, which is 66 respondents $(59.46 \%)$.

Most of the respondents with the position as a head of the section are 54 respondents $(48.65 \%)$. However, those with the position as head of affairs and implementers are also slightly different, that are 41 respondents $(36.94 \%)$. The majority of respondents started joining this company in 2000 or before the year, which amounted to 55 respondents $(49.55 \%)$.

\section{Validity and Reliability Tests}

The results of validity and reliability tests are shown in Table 2.

Tabel 2. Reliability and Validity Test Results

\begin{tabular}{|c|c|c|c|c|c|c|c|c|c|}
\hline Construct & $\begin{array}{l}\text { Composite } \\
\text { Reliability }\end{array}$ & $\begin{array}{c}\text { Cronbach's } \\
\text { Alpha }\end{array}$ & AVE & Data Quality & $\begin{array}{c}\text { Information } \\
\text { Quality }\end{array}$ & $\begin{array}{l}\text { Content } \\
\text { Quality }\end{array}$ & $\begin{array}{l}\text { Quality of } \\
\text { Decision } \\
\text { Making }\end{array}$ & $\begin{array}{l}\text { Business } \\
\text { Intelligence } \\
\text { Scope }\end{array}$ & $\begin{array}{l}\text { Business } \\
\text { Intelligence } \\
\text { Management }\end{array}$ \\
\hline Data Quality & 0,8362 & 0,7539 & 0,5087 & 0,7132 & & & & & \\
\hline Information Quality & 0,8748 & 0,8209 & 0,5832 & 0,7274 & 0,7636 & & & & \\
\hline Content Quality & 0,8314 & 0,7502 & 0,5015 & 0,6078 & 0,6962 & 0,7082 & & & \\
\hline Quality of Decision Making & 0,8754 & 0,8112 & 0,6380 & 0,6567 & 0,7655 & 0,6489 & 0,7987 & & \\
\hline Business Intelligence Scope & 0,9252 & 0,8412 & 0,8608 & 0,4899 & 0,5285 & 0,5337 & 0,5808 & 0,9278 & \\
\hline Business Intelligence Management & 0,8305 & 0,6973 & 0,6211 & 0,5843 & 0,6180 & 0.5780 & 0,5614 & 0,5065 & 0,7881 \\
\hline
\end{tabular}

This study uses convergent validity and discriminant validity in testing the validity. Convergent validity of the measurement model with indicator reflective model is measured based on the correlation between score item or score component and score construct calculated by Partial Least Square (PLS). The reflective size is said to be high if the correlation score is more than 0.7 among the constructs to be measured. However, it is recommended that the value of Average Variance Extracted (AVE) more than 0.5 (Hair et al., 2014).

The assessment of discriminant validity can be done by comparing the value of square root of AVE in each construct with the correlation between other constructs within the model. If the square root of AVE in each construct is greater than the value of correlation between constructs within the model, so the discriminant validity value is said to be good (Hair et al., 2014). The results of convergent and discriminant validity are shown in Table 2.

The results explained that AVE in the construct of BI Management (BM), BI Scope (BS), Data Quality (DQ), Content Quality (CQ), Information Quality (IQ), and Quality of Decision Making (QDM) has resulted in AVE and the loading factor, which is over 0.5. The results indicate that the indicators used in this research are valid or they have met the convergent validity.

In addition, it can be concluded that the square root of AVE in BI Management (BM) construct amounts to 0.7881, Data Quality (DQ) construct 0.7132, Content Quality (CQ) construct 0.7082, Information Quality (IQ) construct 0.7636, BI Scope (BS) construct 0.9278, and Quality of Decision Making (QDM) construct 0.7987 is higher than the correlation among the constructs. Thus, the overall constructs of the data have high discriminant validity.

Related to the reliability test, the reliability test is measured by two criteria that are composite reliability and Cronbach's alpha from the indicator block measuring the construct. To assess the acceptable level of reliability, the composite reliability value should be $>0.70$ and the Cronbach's alpha value should be $\geq 0.60$. Details of composite reliability and Cronbach's alpha analysis results can be seen in Table 2 . 
The results showed that all of the constructs from all of the statements in the questionnaire for the variables of BI management, BI scope, data quality, content quality, information quality, and quality of decision making have a composite reliability $>0.7$ and Cronbach's alpha value $\geq 0.60$. So, it can be concluded that the entire construct has a good reliability.

\section{Research Findings}

Hypotheses test is done by testing the structural model using path coefficient and T-test. The results of this research show that BI management has a positive impact on BI scope $(\mathrm{H} 2)$, content quality (H3), data quality (H4), and information quality (H5). Then, data quality helps to encourage and has a positive impact on the achievement of information quality (H6). In addition, $\mathrm{BI}$ management $(\mathrm{H} 1)$ and information quality $(\mathrm{H} 9)$ directly have a positive impact on the quality of decision-making. But interestingly, BI scope (H7) and content quality (H8) doesn't have significant impact on the quality of decision making. The results of hypotheses test can be seen in Table 3.

Table 3. Hypotheses Test Results

\begin{tabular}{cccc}
\hline Hypotheses & Construct & Path Coefficients & T Statistics \\
\hline H1 & BM $\rightarrow$ QDM & 0,5928 & $4,0083^{* *}$ \\
H2 & BM $\rightarrow$ BS & 0,5093 & $2,7664^{* *}$ \\
H3 & BM $\rightarrow$ CQ & 0,5937 & $3,3676^{* *}$ \\
H4 & BM $\rightarrow$ DQ & 0,6419 & $4,9307^{* *}$ \\
H5 & BM $\rightarrow$ IQ & 0,6503 & $3,7835^{* *}$ \\
H6 & DQ $\rightarrow$ IQ & 0,5736 & $2,7926^{* *}$ \\
H7 & BS $\rightarrow$ QDM & 0,2137 & 0,9813 \\
H8 & CQ $\rightarrow$ QDM & 0,1654 & 0,6296 \\
H9 & IQ $\rightarrow$ QDM & 0,5271 & $2,0787^{*}$ \\
\hline$*$ Significant at 0.05 level & & \\
$* *$ Significant at 0.01 level & &
\end{tabular}

\section{Discussion}

This study shows that BI management positively influences BI scope, content quality, data quality, and information quality. The results indicate that the company should pay attention to the good BI management on all segments or aspects of BI in the company. With a good implementation of BI management in the corporate operations, the users can also understand well about the restrictions that apply to the BI use in the corporate operations. To put it simply, if BI management is effective, employees will understand the dos and don'ts in the use of the corporate BI systems. By paying attention to the detailed BI management implementation, the company will be able to produce the contents needed by users and match with the corporate objectives. In addition, the users' ability to manage BI is also an important factor that supports BI management in order to obtain or produce data with high quality. By considering these, the company can gain quality information, which matches needs.

In relation to the relationship between data quality and information quality, this study shows that data quality has a positive impact on information quality. This means that the company should not only pay attention to the information results that is desired because quality information will be acquired if the data have high quality. The ease of data use in BI system has the impact of to encourage the behavior to use data of BI system as a tool that helps users make decisions and obtain additional information needed so that they feel satisfied in the decision making process. 
This study also found that BI management and information quality have a positive impact on the quality of decision-making. It means that by the existence of BI management, either independently or together with other supporting aspects, the quality of decision-making will be achieved. The company should pay attention to every detail of BI management, as it will drive other aspects to assist in achieving quality decisions in the decision-making process. In addition, the use of quality information in the decision-making process should also be considered. The quality will be acquired if the information used is accurate, which means free of bias and of random error. Therefore, the process of using the information should be observed to avoid data entry errors or omissions in recording transactions in the order that the information produced is accurate and complete for the decision-making process. Thus, the higher the information quality generated from BI system in the corporate operations, the better the quality of the decision made which in turn will improve the company performance.

Nevertheless, another surprising result reveals that BI scope cannot prove a positive impact on the quality of decision-making. This occurs because BI scope in the corporate operations only provides convenience for users to make decisions, but for the quality of the decision highly depends on the ability of users to decide. This means that even if the user is well aware of the limitations of using BI system, the decision made depends on the individual. Then it will not affect the quality of decision making in the company.

In addition, content quality also cannot have a positive impact on the quality of decisionmaking. It occurs because the content in the corporate operations is less appropriate and less needed by the decision makers. In this case, any good content applied or used remains not to affect the quality of the decision on the company. In another word, even if the quality of the content produced or used is good enough, it will not have an influence, since the content is not needed or does not match with the purpose of the decision-making.

In summary, the study found several aspects of BI system that can influence the achievement of decision-making quality. This will be more effective and efficient if the company can pay attention and consider the aspects that are appropriate with the company itself in achieving the quality of decision-making process which in turn match with the company's needs.

\section{Conclusions}

This study examines the impact of BI implementation with the support of BI system aspects such as BI management, data quality, BI scope, content quality, and information quality on the achievement of decision-making quality. Although some aspects that are BI management, data quality, and information quality, both independently and together can have an influence over the achievement of decision-making quality, some other aspects that are BI scope, and content quality do not have an influence over it in this company.

As all prior studies, the present research has few important limitations, particularly the sample size. Furthermore, there have been no particular measures determined for BI construction. However, indicators of measurement quality provide strong support for high reliability and validity.

Despite the limitations, this study would make a contribution theoretically and practically. Theoretically, besides influence on decision-making, this research also supports BI management, data quality, and information quality can influence the quality of decision-making. In addition, this research supports the development of science in the field of accounting information systems and decision support systems, which in turn provide opportunities to future researchers to use the topic or framework of the same model with other aspects of BI systems that support the quality of decision-making. Practically, this research provides new insights for managers and employees at manager level about the impact of business intelligence on decision making and to strengthen their perspective that business intelligence is helpful in strategic decision-making processes within an organization, especially for this fertilizer producer company. Furthermore, 
they can reexamine the BI system in their company and determine the aspects of BI system to be maintained and searching other BI aspects that have an influence and benefits for achieving decision making quality.

\section{References}

Dawson, L., \& Van Belle, J. P. (2013). Critical Success Factors for Business Intelligence in the South African Financial Service Sector. South African Journal of Information Management, 15(11), 545-556.

DeLone, W., \& McLean, E. R. (2003). The DeLone and McLean Model of Information System Success: A Ten Year Update. Journal of Management Information Systems, 19(4), 9-30.

Hair, J. F., Black, W. C., Babin, J. B., \& Anderson, R. E (2014). Multivariate Data Analysis, Seventh Edition. New Jersey: Pearson Education Inc.

Hadeel, M. (2012). The Impact of Business Intelligence and Decision Support on the Quality of Decision Making: An Empirical Study on Five Stars Hotels in Amman Capital. Middle East University.

Hawking, P., \& Sellitto, C. (2010). Business Intelligence ( BI ) Critical Success Factors. Paper presented in 21st Australasian Conference on Information Systems. Brisbane, Queensland, Australia, 01-03 December.

Hou, C. K. (2014). User Acceptance of Business Intelligence Systems in Taiwan's Electronics Industry. Social Behavior and Personality: An International Journal, 42(949), 583-596.

Juliusson, E. Á., Karlsson, N., \& Gärling, T. (2010). European Journal of Cognitive Weighing the Past and the Future in Decision Making. European Journal of Cognitive Psychology, 17(4), 561 575 .

Korte, D., Ariyachandra, T., \& Frolick, M. (2013). Business Intelligence in the Hospitality Industry. International Journal of Innovation, Management, and Technology, 4(4), 429-434.

Monfared, J. H., \& Akbari, Z. (2019). Using Business Intelligence Capabilities to Improve the Quality of Decision-Making: A Case Study of Mellat Bank. Internasional Journal of Economics and Management Engineering. 13(2), 147-158

O’Brien, J. A., \& Marakas, G. M. (2011). Management information systems (10th ed.). New York, NY: The McGraw-Hill Companies.

Olbrich, S., Pöppelbuß, J. \& Niehaves, B. (2012). Critical Contextual Success Factors for Business Intelligence: A Delphi Study on Their Relevance, Variability, and Controllability. Paper presented in 45th Hawaii International Conference on System Sciences. Honolulu, Hawaii, USA, 04-07 January, 4148-4157.

Peters, M., \& Wieder, B. (2013). Business Intelligence Systems for Competitively Advantageous Performance Management Capabilities: Theory and Empirics. Paper presented in AFAANZ Conference. Perth, Australia, 07-09 July.

Redman, T. C. (2008). Data Driven: Profiting from Your Most Important Business Asset. MIT Information Quality Industry Symposium. Retrieved from http://sebokwiki.org/ wiki/Data_Driven:_Profiting_from_Your_Most_Important_Business_Asset accessed January 2016.

Ştefan, M. D. (2009). Improving The Quality of The Decision Making by Using Business Intelligence Solutions. Economic science Series, 18(4), 996-1000.

Sohollo, A. (2011). Using business intelligence in IT governance decision making. In Nüttgens, 
M., Gadatsch, A., Kautz, K., Schirmer, I., \& Blinn, N. (Eds.). Governance and Sustainability in IS (3-15). Germany: Springer.

Venkatesh, V., Setia, P., \& Joglekar, S. (2013). Leveraging Digital Technologies: How Information Quality Leads to Localized Capabilities and Customer Service Performance. MIS Quarterly, 37(2), 565-590.

Wieder, B., Ossimitz, M., \& Chamoni, P. (2012). The Impact of Business Intelligence Tools on Performance: A User Satisfactory Paradox. International Journal of Economic Sciences and Applied Research, 5(3), 7-23.

Wieder, B., \& Ossimitz, M. (2015). The Impact of Business Intelligence on the Quality of Decision Making - A Mediation Model. Paper presented in Conference on ENTERprise Information Systems. Vilamoura, Portugal, 07-09 October, 1163-1171. 